Quim. Nova, Vol. 35, No. 1, 22-29, 2012

\title{
CHUMBO E ZINCO EM ÁGUAS E SEDIMENTOS DE ÁREA DE MINERAÇÃO E METALURGIA DE METAIS
}

\author{
Vander de Freitas Melo*, Maísa de Andrade, Araína Hulmann Batista e Nerilde Favaretto \\ Departamento de Solos e Engenharia Agrícola, Universidade Federal do Paraná, Rua dos Funcionários, 1540, \\ 80035-050 Curitiba - PR, Brasil \\ Marco Tadeu Grassi e Mônica Soares de Campos \\ Departamento de Química, Universidade Federal do Paraná, CP 19081, 81531-990 Curitiba - PR, Brasil
}

Recebido em 26/11/10; aceito em 16/6/11; publicado na web em 9/8/11

\begin{abstract}
LEAD AND ZINC IN WATER AND SEDIMENTS OF A METAL MINING AND METALLURGY AREA. Lead metallurgy at Adrianópolis is the largest environmental problem of Paraná, Brazil. The objective of this study was to determine $\mathrm{Pb}$ and $\mathrm{Zn}$ levels in water and sediment in two catchments by different extraction methods. The high levels of lead in water in most of samples do not allow the human use. Total $\mathrm{Pb}$ concentration as high as $795.3 \mu \mathrm{g} \mathrm{L}^{-1}$ was observed in Ribeira River bank, in a pluvial water stream flowering from a abandoned factory. Due to the high $\mathrm{Pb}$ levels in sediments from some sites (maximum of $24,300 \mathrm{mg} \mathrm{kg}^{-1}$ ) is recommended to avoid the water turbulence.
\end{abstract}

Keywords: environmental contamination; heavy metal; total and soluble forms.

\section{INTRODUÇÃO}

O aporte de metais traços em corpos aquáticos pode ocorrer naturalmente por meio de processos geoquímicos e intemperismo do material de origem ou como resultado de atividades antrópicas. Dentre as fontes diretamente relacionadas a essas atividades podemos citar, entre outras, o descarte de efluentes industriais e domésticos e a carga difusa urbana e agrícola. ${ }^{1}$

As atividades mineradoras também são fontes conhecidas de aporte de metais traços para os sistemas aquáticos. ${ }^{2-4}$ A liberação desses poluentes para o meio pode ocorrer por meio da lixiviação de rejeitos estocados, dos efeitos de erosão e do rompimento de barragens e, uma vez nos corpos aquáticos, podem ser transportados ocasionando contaminação de ambientes distantes das fontes de poluição. ${ }^{5}$ Silva et $a l .^{6}$ encontraram concentrações extremamente altas de $\mathrm{Pb}, \mathrm{Zn}$ e $\mathrm{Cd}$ em sedimentos coletados nos primeiros $2,5 \mathrm{~km}$ a partir da mina abandonada de Coval da Mó, em Portugal.

$\mathrm{Na}$ água, os metais traços podem estar presentes em diferentes formas ou espécies dependendo das condições físicas e químicas do meio, como íons livres, complexados com compostos solúveis orgânicos ou minerais (fração dissolvida), associados à matéria orgânica ou mineral insolúvel (fração particulada). A presença de material particulado em suspensão, formada por vários compostos, como material orgânico e óxidos metálicos, influencia diretamente o comportamento dos elementos, pois afeta a fração dissolvida, o tempo de residência e, consequentemente, a biodisponibilidade e o transporte no curso de água. ${ }^{7,8}$ Devido à importância da partição de metais traços entre as fases dissolvida e particulada, a toxicidade não pode ser atribuída exclusivamente à fração total presente no meio. Apesar disso, mesmo sendo um dos padrões de qualidade de água mais relevantes no Brasil, a Resolução 357 do Conselho Nacional de Meio Ambiente, de março de 2005, contempla valores máximos permissíveis referentes somente apenas à fração total para a grande maioria dos metais. ${ }^{9}$

Os sedimentos são formados por partículas minerais e orgânicas de vários tamanhos que se encontram em contato com a porção inferior dos corpos d'água. O sedimento é o compartimento de maior

\footnotetext{
*e-mail: vanderfm@ufpr.br
}

concentração de metais, ${ }^{10}$ os quais podem ser liberados por alterações nas condições biológicas, físicas e químicas, como $\mathrm{pH}$ e potencial redox, ${ }^{1,11,12}$ o que ocasiona a contaminação da água e a transferência e bioacumulação desses poluentes para a cadeia trófica, ${ }^{11,13,14}$ Desta forma, dependendo de sua natureza e do ambiente em que se encontram, os sedimentos podem representar fonte ou sumidouro para os metais traços provenientes das águas. ${ }^{15}$

O presente trabalho foi conduzido no município de Adrianópolis, localizado às margens do Rio Ribeira, estado do Paraná. Nesse local foram desenvolvidas durante 50 anos as atividades mineração da galena $(\mathrm{PbS})$ e de primeira fusão de $\mathrm{Pb}$. Apesar de o principal enfoque estar relacionado ao $\mathrm{Pb}$, outros elementos, como $\mathrm{Ag}$ e $\mathrm{Zn}$, também foram explorados e beneficiados na região. ${ }^{16} \mathrm{Em} \mathrm{1995,} \mathrm{a}$ mineradora encerrou suas atividades deixando a céu aberto, sem nenhuma proteção, cerca de $180 \mathrm{Gg}$ de resíduos de beneficiamento da galena. ${ }^{17}$ Eysink ${ }^{18}$ observou que os sedimentos do Rio Ribeira apresentavam elevados teores de metais traços, principalmente $\mathrm{Pb}$, em locais próximos à fábrica. Estudos mais recentes na área demonstraram que os efeitos da mineração e metalurgia de $\mathrm{Pb}$ ainda se faziam presentes. Kummer ${ }^{19}$ determinou as características químicas e mineralógicas e promoveu a especiação de $\mathrm{Pb}$ e $\mathrm{Zn}$ dos solos por meio de extrações sequenciais. A contaminação dos solos argilosos próximos à fábrica e ao Rio Ribeira por materiais particulados das chaminés mostrou-se mais prejudicial ao ambiente em virtude dos maiores teores totais $\left(19.434,0 \mathrm{mg} \mathrm{kg}^{-1}\right)$ e de formas de maior solubilidade de $\mathrm{Pb}$ (trocável - extraído com $\mathrm{Ca}\left(\mathrm{NO}_{3}\right)_{2} 0,5 \mathrm{~mol} \mathrm{~L}^{-1}$ - 903,6 $\mathrm{mg} \mathrm{kg}^{-1}$ ). Nos trabalhos de Barros et al. ${ }^{20,21}$ foram gerados indicadores de qualidade dos solos por meio de avaliações físicas, químicas, microbiológicas, da mesofauna e de plantas nativas: o maior número de bactérias esporuláveis no solo mais poluído foi interpretado como um mecanismo de resistência desses organismos aos elevados teores de $\mathrm{Pb}$. Os autores observaram também que a maioria das plantas nativas estudadas apresentou toxidez de $\mathrm{Pb}$ e $\mathrm{Zn}$, sendo encontrados os maiores teores desses metais nas raízes das plantas (máximo de 939,9 $\mathrm{mg} \mathrm{kg}^{-1}$ ).

Com relação à contaminação da população no entorno da área de estudo, Paolielo et al. ${ }^{22}$ coletaram amostras de sangue de crianças em três municípios da região do Vale do Ribeira, em 1999 e 2000, e estabeleceram relação direta entre a distância das residências onde 
os minérios eram processados e o teor de $\mathrm{Pb}$ no sangue. Em estudo similar, Cunha ${ }^{23}$ avaliou o sangue de 335 crianças em idade escolar (7 a 14 anos), que moravam no entorno da antiga área de mineração (Vila Mota), e constatou que $70 \%$ das crianças apresentaram concentrações de $\mathrm{Pb}$ três vezes superiores aos limites preconizados pela Organização Mundial de Saúde.

$\mathrm{Na}$ atualidade, a área sob influência direta das atividades de mineração e metalurgia de $\mathrm{Pb}$ em Adrianópolis constitui o maior passivo ambiental do estado do Paraná e se tornou, também, grande problema de saúde pública pela contaminação da população. Dessa forma, estudos de diagnóstico na área são fundamentais, principalmente, quando se avalia a qualidade da água que dissipa da mina e é utilizada pelos moradores. Nesse trabalho são apresentados os teores de $\mathrm{Pb}$ e $\mathrm{Zn}$ em amostras de água superficiais e subterrâneas e sedimentos coletados em corpos aquáticos, com diferentes distâncias da usina de beneficiamento dos metais traços. Procurou-se, também, relacionar os diferentes ambientes de contaminação dos solos (material particulado ou disposição direta de resíduos sobre a superfície) com a contaminação dos cursos d'água e dos sedimentos.

\section{PARTE EXPERIMENTAL}

\section{Descrição da área}

A área estudada situa-se no município de Adrianópolis (PR), próxima às margens do Rio Ribeira. A Bacia do Alto Vale do Ribeira ocupa uma área aproximada de $25.000 \mathrm{~km}^{2}$, percorre $220 \mathrm{~km}$ em terras paranaenses e $360 \mathrm{~km}$ no estado de São Paulo, compreendendo 32 municípios. ${ }^{24} \mathrm{O}$ Rio Ribeira de Iguape é classificado, segundo a Resolução CONAMA 357/2005, ${ }^{9}$ como um corpo d'água classe II em todo o seu percurso. Essa classificação disponibiliza a utilização de suas águas, entre outras finalidades, para consumo humano após tratamento convencional, recreação de contato primário (natação, esqui aquático e mergulho), irrigação de hortaliças, plantas, aquicultura e atividade de pesca.

O clima da região, segundo a classificação de Koppen, é subtropical úmido mesotérmico, com verões quentes e com concentração de chuvas (temperatura média superior a $22^{\circ} \mathrm{C}$ ), invernos com geadas pouco frequentes (temperatura média inferior a $18^{\circ} \mathrm{C}$ ), sem estação seca definida. As médias de precipitação pluviométrica anual da região ficam em torno de 1.500 a $2.500 \mathrm{~mm}$.

A área de estudo possui relevo montanhoso, constituída por morros com encostas retilíneas e topos curtos, o que favorece, juntamente com o predomínio de solos rasos (ausência de horizonte B), os processos erosivos. ${ }^{20}$

Na Figura 1S, material suplementar, e na Tabela 1 são mostradas a localização e algumas características dos pontos de coleta das amostras. Com a finalidade de avaliar as concentrações naturais de $\mathrm{Pb}$ e $\mathrm{Zn}$ da região, foram coletadas amostras nas duas únicas nascentes (A e B) da área sob influência direta das atividades de mineração e metalurgia de metais traços. Esses pontos de coleta foram considerados como referências, devido ao fato de se localizarem em uma posição mais elevada e supostamente não foram impactados pelas atividades de mineração (pontos 1 e 9). A partir da localização de cada nascente foram coletadas amostras de água e de sedimento, até o rio Ribeira. Para a avaliação de $\mathrm{Pb}$ e $\mathrm{Zn}$ na água subterrânea foram coletadas amostras no interior de um túnel de mineração, a aproximadamente $300 \mathrm{~m}$ de distância de sua entrada (ponto 5). Foi avaliada a água consumida pela população das vilas habitadas no entorno da usina de beneficiamento (pontos 20 e 21).

A coleta e a preservação das amostras foram realizadas conforme recomendações do APHA. ${ }^{25}$ Coletaram-se amostras de água e sedimentos em quatro períodos estacionais, referentes ao outono
Tabela 1. Localização e características dos pontos de amostragem

\begin{tabular}{|c|c|c|c|}
\hline Ponto & $\begin{array}{c}\text { Coordenadas } \\
\text { geográficas }\end{array}$ & $\begin{array}{l}\text { Altitude } \\
(\mathrm{m})\end{array}$ & Descrição \\
\hline 1 & $\begin{array}{l}24^{\circ} 41^{\prime} 41^{\prime \prime} \mathrm{S} \\
48^{\circ} 54^{\prime} 44^{\prime \prime} \mathrm{W}\end{array}$ & 396 & $\begin{array}{l}\text { Nascente A (ponto mais alto), to } \\
\text { mado como referência. Aparente- } \\
\text { mente sem atividade antrópica. }\end{array}$ \\
\hline 2 & $\begin{array}{l}24^{\circ} 41^{\prime} 36^{\prime \prime} \mathrm{S} \\
48^{\circ} 54^{\prime} 42^{\prime \prime} \mathrm{W}\end{array}$ & 387 & \multirow{3}{*}{$\begin{array}{l}\text { Pontos sequencialmente abaixo } \\
\text { do ponto } 1 \text {. Água superficial da } \\
\text { região mais alta do terreno. Após } \\
\text { o ponto } 4 \text {, a água se infiltra nas } \\
\text { galerias deixadas pela mineração } \\
\text { voltando à superfície apenas no } \\
\text { ponto } 6 \text {. }\end{array}$} \\
\hline 3 & $\begin{array}{l}24^{\circ} 41^{\prime} 30^{\prime \prime} \mathrm{S} \\
48^{\circ} 54^{\prime} 41^{\prime \prime} \mathrm{W}\end{array}$ & 376 & \\
\hline 4 & $\begin{array}{l}24^{\circ} 4^{\prime} 27^{\prime \prime} \mathrm{S} \\
48^{\circ} 54^{\prime} 41^{\prime \prime} \mathrm{W}\end{array}$ & 363 & \\
\hline 5 & $\begin{array}{c}\text { GPS } \\
\text { sem sinal }\end{array}$ & $\begin{array}{c}\text { GPS } \\
\text { sem sinal }\end{array}$ & $\begin{array}{l}\text { Água subterrânea a cerca de } \\
300 \text { m no interior de um túnel de } \\
\text { mineração. }\end{array}$ \\
\hline
\end{tabular}

\begin{tabular}{|c|c|c|c|}
\hline 6 & $\begin{array}{c}24^{\circ} 41^{\prime} 3 \text { ' } \mathrm{S} \\
48^{\circ} 54^{\prime} 35^{\prime \prime} \mathrm{W}\end{array}$ & 199 & \multirow{3}{*}{$\begin{array}{l}\text { Pontos após a saída da água do } \\
\text { túnel de mineração. }\end{array}$} \\
\hline 7 & $\begin{array}{l}24^{\circ} 41^{\prime} 1^{\prime \prime} \mathrm{S} \\
48^{\circ} 54^{\prime} 34^{\prime \prime} \mathrm{W}\end{array}$ & 189 & \\
\hline 8 & $\begin{array}{c}24^{\circ} 41^{\prime} 0 \text { " ' S } \\
48^{\circ} 54^{\prime} 34^{\prime \prime} \mathrm{W}\end{array}$ & 184 & \\
\hline 9 & $\begin{array}{l}24^{\circ} 40^{\prime} 58^{\prime \prime} \mathrm{S} \\
48^{\circ} 54^{\prime} \cdot 7 \text { ' } \mathrm{W}\end{array}$ & 207 & $\begin{array}{l}\text { Nascente B (ponto mais alto), to- } \\
\text { mado como referência. Aparente- } \\
\text { mente sem atividade antrópica. }\end{array}$ \\
\hline 10 & $\begin{array}{c}24^{\circ} 4^{\prime} 0 " \mathrm{~S} \\
48^{\circ} 54^{\prime} 20^{\prime \prime} \mathrm{W}\end{array}$ & 188 & $\begin{array}{l}\text { Água superficial coletada após a } \\
\text { amostra de referência (ponto 9). }\end{array}$ \\
\hline 11 & $\begin{array}{l}24^{\circ} 40^{\prime} 58^{\prime \prime} \mathrm{S} \\
48^{\circ} 54^{\prime} 30^{\prime \prime} \mathrm{W}\end{array}$ & 186 & $\begin{array}{l}\text { Água superficial em área bastante } \\
\text { antropizada. }\end{array}$ \\
\hline 12 & $\begin{array}{l}24^{\circ} 40^{\prime} 57^{\prime \prime} \mathrm{S} \\
48^{\circ} 54^{\prime} 35^{\prime \prime} \mathrm{W}\end{array}$ & 161 & \multirow{4}{*}{$\begin{array}{l}\text { Água superficial de convergência } \\
\text { das nascentes } 1 \text { e } 9 \text { que passa ao } \\
\text { lado da fábrica e deságua no Rio } \\
\text { Ribeira. }\end{array}$} \\
\hline 13 & $\begin{array}{l}24^{\circ} 40^{\prime} 55^{\prime \prime} \mathrm{S} \\
48^{\circ} 54^{\prime} 37^{\prime \prime} \mathrm{W}\end{array}$ & 160 & \\
\hline 14 & $\begin{array}{l}24^{\circ} 40^{\prime} 54^{\prime \prime} \mathrm{S} \\
48^{\circ} 54^{\prime} 39^{\prime \prime} \mathrm{W}\end{array}$ & 158 & \\
\hline 15 & $\begin{array}{l}24^{\circ} 40^{\prime} 51^{\prime \prime} \mathrm{S} \\
48^{\circ} 54^{\prime} 42^{\prime \prime} \mathrm{W}\end{array}$ & 156 & \\
\hline 16 & $\begin{array}{l}24^{\circ} 40^{\prime} 54^{\prime \prime} \mathrm{S} \\
48^{\circ} 54^{\prime} 44^{\prime \prime} \mathrm{W}\end{array}$ & 154 & $\begin{array}{l}\text { Água de lavagem da fábrica, a } \\
\text { aproximadamente } 5 \mathrm{~m} \text { do Rio } \\
\text { Ribeira. A água pluvial que passa } \\
\text { pela fábrica solubiliza/transporta } \\
\text { partículas ricas em metais traços } \\
\text { para o Rio Ribeira. }\end{array}$ \\
\hline 17 & $\begin{array}{l}24^{\circ} 40^{\prime} 54^{\prime \prime} \mathrm{S} \\
48^{\circ} 54^{\prime} 45^{\prime \prime} \mathrm{W}\end{array}$ & 151 & Água e sedimento do Rio Ribeira. \\
\hline 18 & $\begin{array}{l}24^{\circ} 40^{\prime} 59^{\prime \prime} \mathrm{S} \\
48^{\circ} 54^{\prime} 52^{\prime \prime} \mathrm{W}\end{array}$ & 157 & $\begin{array}{l}\text { Ponto após a saída da água do } \\
\text { túnel de mineração. }\end{array}$ \\
\hline 19 & $\begin{array}{l}24^{\circ} 40^{\prime} 49^{\prime \prime} \mathrm{S} \\
48^{\circ} 55^{\prime} 5^{\prime \prime} \mathrm{W}\end{array}$ & 160 & $\begin{array}{l}\text { Água e sedimento do Rio Ribeira. } \\
\text { Ponto a montante da área de } \\
\text { mineração (amostra referência } \\
\text { para o ponto } 17 \text { ). }\end{array}$ \\
\hline 20 & $\begin{array}{l}24^{\circ} 40^{\prime} 39^{\prime \prime} \mathrm{S} \\
48^{\circ} 55^{\prime} 29^{\prime \prime} \mathrm{W}\end{array}$ & 200 & $\begin{array}{l}\text { Água canalizada proveniente de } \\
\text { uma nascente a montante da área, } \\
\text { ao lado de uma igreja. }\end{array}$ \\
\hline 21 & $\begin{array}{l}24^{\circ} 40^{\prime} 19^{\prime \prime} \mathrm{S} \\
48^{\circ} 53^{\prime} 57^{\prime \prime} \mathrm{W}\end{array}$ & 204 & $\begin{array}{l}\text { Poço artesiano de captação e } \\
\text { distribuição de água para a popu- } \\
\text { lação da Vila Motta, a jusante } \\
\text { da fábrica. }\end{array}$ \\
\hline
\end{tabular}

(22/5/2007), inverno (3/9/2007), primavera (26/11/2007) e verão (28/1/2008). Foram coletadas no total 84 amostras de água e 76 amostras de sedimento.

As amostras de sedimento foram secas em estufa a $40{ }^{\circ} \mathrm{C}$ e peneiradas em malha de $2 \mathrm{~mm}$. Os teores de areia, silte e argila foram determinados pelo método da pipeta. ${ }^{26}$ Os teores de $\mathrm{Pb}$ e $\mathrm{Zn}$ foram determinados em duas frações: pseudototal e trocável. Para obtenção dos teores pseudototais foi realizada a digestão das amostras em 
micro-ondas (Start D, Milestone), com $\mathrm{HNO}_{3}$ e $\mathrm{HCl}$ concentrados (relação 3:1), segundo o método SW 846-3051A. ${ }^{27}$ Após o resfriamento, as suspensões foram filtradas em papel de filtro qualitativo. As formas trocáveis (complexo de esfera externa ou adsorção não específica) de $\mathrm{Pb}$ e $\mathrm{Zn}$ dos sedimentos foram extraídas com $\mathrm{BaCl}_{2}$ $0,1 \mathrm{~mol} \mathrm{~L}^{-1}$, em agitação circular por $2 \mathrm{~h}$ e posterior centrifugação para coleta do extrato. ${ }^{28}$

A determinação da concentração de sólidos totais em suspensão (STS) foi realizada de acordo com as recomendações do APHA. ${ }^{25}$

Os teores de $\mathrm{Pb}$ e $\mathrm{Zn}$ nas amostras de água foram determinados nas frações total (TOT) e solúvel (SOL). Para a fração TOT foi realizada a digestão das amostras de água em forno micro-ondas, procedendo-se adaptações do método SW 846-3015A. ${ }^{29}$ A determinação dos teores solúveis de $\mathrm{Pb}$ e $\mathrm{Zn}$ foi realizada de acordo com o método 3030B da APHA, ${ }^{25} \mathrm{em} 20 \mathrm{~mL}$ de água filtrada (membrana de éster de celulose de $0,45 \mu \mathrm{m}$ de porosidade) e acidificada com $\mathrm{HNO}_{3}$ até $\mathrm{pH}$ 2. Em todos os procedimentos foram utilizados ácidos de grau suprapuro (Merck).

Os teores na fração particulada (PAR) $\left(\mu \mathrm{g} \mathrm{g}^{-1}\right)$ foram obtidos por diferença entre os teores das frações anteriores, aplicando-se a seguinte equação: $\mathrm{PAR}=($ TOT $-\mathrm{SOL}) / \mathrm{STS}$. Nos casos onde o teor de $\mathrm{Pb}$ ou $\mathrm{Zn}$ na fração SOL ficou abaixo do limite de detecção $\left(1,0 \mu \mathrm{g} \mathrm{L}^{-1}\right)$, este valor foi utilizado no cálculo da fração particulada (PAR).

Com a finalidade de avaliar possíveis contaminações nos reagentes e materiais utilizados, foram feitas determinações em 3 soluções de brancos analíticos para frações TOT e SOL. Os brancos analíticos foram preparados com água ultrapura (Milli-Q), ácidos de grau suprapuro, tendo sido submetidos aos mesmos processos utilizados nas amostras.

A determinação de $\mathrm{Pb}$ e $\mathrm{Zn}$ foi realizada por meio de espectrometria de emissão ótica com fonte de plasma indutivamente acoplado (ICP-OES), utilizando-se um equipamento modelo iCAP 6500 da Thermo Scientific, visão axial e padronização interna com ítrio. A exatidão do método foi avaliada por meio de recuperação de analito em material de referência certificado NIST 1643e (Trace Elements in Water).
Para efeito de comparação foram considerados os dois padrões de qualidade de águas julgados mais relevantes no país, a Portaria 518 do Ministério da Saúde ${ }^{30}$ e a Resolução 357 do Conselho Nacional de Meio Ambiente. ${ }^{9}$

\section{RESULTADOS E DISCUSSÃO}

\section{Características gerais das amostras de água e de sedimento}

Um dos fatores que controlam a adsorção e retenção de metais traços no sedimento é o tamanho das partículas, sendo reconhecida a ligação à fração coloidal, devido, principalmente, à elevada densidade de carga negativa e área superficial. ${ }^{11}$ A textura das amostras de sedimento variou bastante, com predomínio das frações areia (amostras 7 a 19) e silte (amostras 1 a 6) (Tabela 2). A grande maioria dos solos da área apresenta textura argilosa, ${ }^{31}$ compatível com o substrato calcáreo/granítico da região. ${ }^{32}$

Quanto maior a velocidade do fluxo da água superficial mais se observou acúmulo preferencial da fração areia, pois o transporte de silte e argila nessas condições é facilitado. O contrário foi observado nos pontos 1 a 5 . Mesmo tomando amostras próximas em cada ponto, a grande heterogeneidade dos sedimentos determinou a variação no teor de argila entre as coletas sazonais (Tabela 2).

Todas as amostras de água, com exceção dos pontos 1 e 21 na coleta de setembro apresentaram $\mathrm{pH}$ acima de 7,0 (Figura 1). O meio básico favorece a precipitação e as formas particuladas e coloidais e a decantação dos metais traços no compartimento sedimentar. $^{7}$

Outro parâmetro importante para a avaliação da presença de metais na água é a determinação dos sólidos totais em suspensão (STS) (Tabela 3). A concentração de STS variou entre os pontos e entre as épocas de amostragens. De maneira geral, o mês de janeiro apresentou os menores valores de STS (média de $0,0135 \mathrm{~g} \mathrm{~L}^{-1}$ ), pois não houve registro de chuvas nos dias que antecederam a coleta, desfavorecendo a turbidez.

Tabela 2. Textura $\left(\mathrm{g} \mathrm{kg}^{-1}\right)$ das amostras de sedimento

\begin{tabular}{|c|c|c|c|c|c|c|c|c|c|c|c|c|}
\hline \multirow[b]{3}{*}{ Ponto } & \multicolumn{12}{|c|}{ Mês de coleta } \\
\hline & \multicolumn{3}{|c|}{ Maio } & \multicolumn{3}{|c|}{ Setembro } & \multicolumn{3}{|c|}{ Novembro } & \multicolumn{3}{|c|}{ Janeiro } \\
\hline & Areia & Silte & Argila & Areia & Silte & Argila & Areia & Silte & Argila & Areia & Silte & Argila \\
\hline 1 & 226 & 572 & 202 & 265 & 526 & 209 & 342 & 421 & 237 & 394 & 577 & 29 \\
\hline 2 & 195 & 599 & 206 & 283 & 534 & 183 & 381 & 429 & 190 & 400 & 506 & 94 \\
\hline 3 & 198 & 546 & 256 & 365 & 449 & 186 & 325 & 469 & 206 & 364 & 377 & 259 \\
\hline 4 & 227 & 601 & 172 & 325 & 473 & 202 & 408 & 403 & 189 & 361 & 405 & 234 \\
\hline 5 & 446 & 489 & 65 & 527 & 389 & 84 & 595 & 317 & 88 & 656 & 323 & 21 \\
\hline 6 & 136 & 713 & 151 & 699 & 223 & 78 & 809 & 99 & 92 & 471 & 519 & 10 \\
\hline 7 & 760 & 186 & 54 & 792 & 134 & 74 & 793 & 118 & 89 & 783 & 159 & 58 \\
\hline 8 & 740 & 190 & 70 & 665 & 230 & 105 & 656 & 222 & 122 & 709 & 274 & 17 \\
\hline 9 & 820 & 119 & 61 & 848 & 72 & 80 & 855 & 70 & 75 & 930 & 13 & 57 \\
\hline 10 & 863 & 89 & 48 & 722 & 131 & 147 & 871 & 46 & 83 & 943 & 47 & 10 \\
\hline 11 & 787 & 146 & 67 & 878 & 49 & 73 & 872 & 50 & 78 & 953 & 1 & 46 \\
\hline 12 & 666 & 218 & 116 & 746 & 152 & 102 & 640 & 205 & 155 & 933 & 18 & 49 \\
\hline 13 & 824 & 115 & 61 & 643 & 239 & 118 & 880 & 48 & 72 & 785 & 111 & 104 \\
\hline 14 & 702 & 182 & 116 & 632 & 190 & 178 & 834 & 66 & 100 & 615 & 231 & 154 \\
\hline 15 & 854 & 99 & 47 & 896 & 58 & 46 & 362 & 479 & 159 & 857 & 135 & 8 \\
\hline 16 & 591 & 331 & 78 & 811 & 103 & 86 & 798 & 117 & 85 & 697 & 288 & 15 \\
\hline 17 & 615 & 234 & 151 & 701 & 165 & 134 & 695 & 154 & 151 & 551 & 437 & 12 \\
\hline 18 & 674 & 233 & 93 & 673 & 189 & 138 & 779 & 150 & 71 & 441 & 522 & 37 \\
\hline 19 & 617 & 265 & 118 & 758 & 136 & 106 & 78 & 533 & 389 & 615 & 371 & 14 \\
\hline Média & 576 & 312 & 112 & 644 & 234 & 123 & 630 & 231 & 138 & 656 & 280 & 65 \\
\hline
\end{tabular}




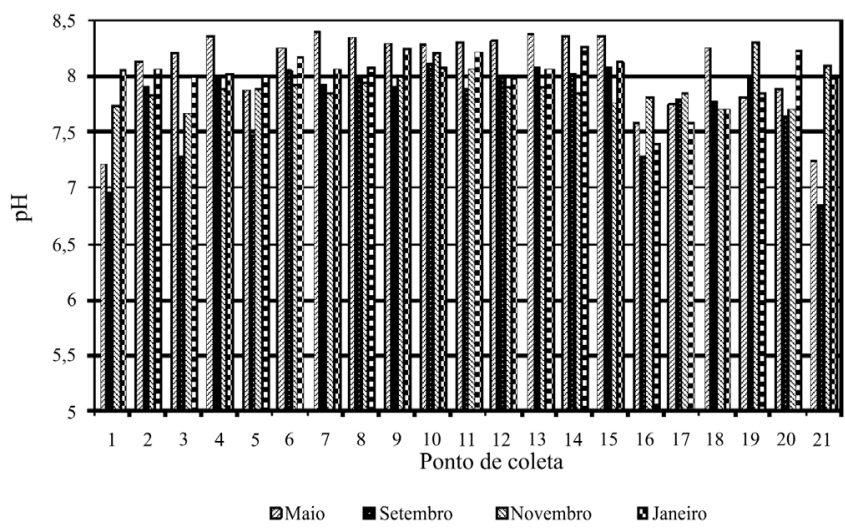

Figura 1. Valores de pH das amostras de água

\section{Chumbo nas amostras de água e de sedimento}

Devido à baixa solubilidade dos compostos presentes nos solos e sedimentos, a maior parte do $\mathrm{Pb}$ é retida nesses compartimentos e, consequentemente, uma concentração baixa é transportada em águas de superfície ou subterrâneas. ${ }^{10}$

Os resultados das amostras de águas são apresentados na Tabela 4. Embora, de maneira geral, o ponto 9 tenha apresentado concentrações mais altas do que o ponto 1 , nenhuma amostra referente às nascentes (pontos 1 e 9), apresentou teores totais de $\mathrm{Pb}$ acima do valor máximo permitido pela Portaria 518 do Ministério da Saúde e pela Resolução CONAMA 357 (classe 1) para esse elemento $\left(10,0 \mu \mathrm{g} \mathrm{L}^{-1}\right)$.

Nos sedimentos, os teores de $\mathrm{Pb}$ no ponto 9 foram preferencialmente mais baixos em relação ao ponto 1 (Tabela 5). Esse comportamento pode ser atribuído à diferença de granulometria dos sedimentos (ponto 1 mais argiloso - Tabela 2) e do $\mathrm{pH}$ da água (ponto 1 mais alcalino - Figura 1) nas duas nascentes.

Os pontos 2, 3 e 4, situados na mesma linha de drenagem do ponto 1 ,
Tabela 3. Sólidos totais em suspensão $\left(\mathrm{g} \mathrm{L}^{-1}\right)$ nas amostras de água

\begin{tabular}{ccccc}
\hline & Maio & Setembro & Novembro & Janeiro \\
\hline 1 & 0,0875 & 0,1030 & 0,0215 & $\mathrm{nd}^{1}$ \\
2 & 0,0575 & 0,0825 & 0,0605 & 0,0065 \\
3 & 0,0945 & 0,1210 & 0,1150 & 0,0060 \\
4 & 0,0420 & 0,0735 & 0,0645 & 0,0115 \\
5 & 0,0345 & 0,0935 & 0,0270 & 0,0065 \\
6 & 0,0705 & 0,0795 & 0,0310 & 0,0180 \\
7 & 0,0380 & 0,0845 & 0,0255 & 0,0080 \\
8 & 0,0700 & 0,0810 & 0,0280 & 0,0085 \\
9 & 0,0550 & 0,0615 & 0,0165 & 0,0060 \\
10 & 0,0750 & 0,0340 & 0,0155 & 0,0060 \\
11 & 0,0430 & 0,0355 & 0,0140 & 0,0065 \\
12 & 0,0565 & 0,0640 & 0,0415 & 0,0060 \\
13 & 0,0840 & 0,0390 & 0,0210 & 0,0060 \\
14 & 0,0410 & 0,0365 & 0,0635 & 0,0060 \\
15 & 0,0350 & 0,0805 & 0,0285 & 0,0060 \\
16 & 0,0415 & 0,0105 & 0,0175 & 0,1295 \\
17 & 0,0830 & 0,0125 & 0,0160 & 0,0240 \\
18 & 0,0270 & 0,0270 & 0,0165 & 0,0080 \\
19 & 0,0740 & 0,0105 & 0,0170 & 0,0085 \\
20 & 0,0615 & 0,0320 & 0,0300 & 0,0003 \\
21 & 0,0180 & 0,0325 & 0,0170 & 0,0060 \\
Média & 0,0566 & 0,0569 & 0,0327 & 0,0135 \\
\hline & 0 & &
\end{tabular}

${ }^{1}$ não determinado pela baixa quantidade de material particulado $(<0,0001 \mathrm{~g})$.

apresentaram, de maneira geral, acumulação progressiva de $\mathrm{Pb}$ na água, com maiores teores para o ponto 4 (Tabela 4). A possibilidade de troca do $\mathrm{Pb}$ do sedimtableento para formas solúveis na água nos pontos 1 a 4 é pequena, pois não se verificaram formas trocáveis do metal nos sedimentos (Tabela 5). A falta de relação entre os meses

Tabela 4. Teores de $\mathrm{Pb}$ total (TOT - $\left.\mu \mathrm{g} \mathrm{L}^{-1}\right)$, solúvel $\left(\mathrm{SOL}-\mu \mathrm{g} \mathrm{L^{-1 }}\right)$ e particulado (PAR - $\left.\mu \mathrm{g} \mathrm{g}^{-1}\right)$ nas amostras de água

\begin{tabular}{|c|c|c|c|c|c|c|c|c|c|c|c|c|}
\hline \multirow[b]{3}{*}{ Ponto } & \multicolumn{12}{|c|}{ Mês de coleta } \\
\hline & \multicolumn{3}{|c|}{ Maio } & \multicolumn{3}{|c|}{ Setembro } & \multicolumn{3}{|c|}{ Novembro } & \multicolumn{3}{|c|}{ Janeiro } \\
\hline & TOT & SOL & PAR & TOT & SOL & PAR & TOT & SOL & PAR & TOT & SOL & PAR \\
\hline 1 & 2,0 & $<1,0$ & 11,4 & 1,9 & $<1,0$ & 8,7 & 5,1 & $<1,0$ & 190 & 3,2 & $<1,0$ & $\mathrm{nd}^{1}$ \\
\hline 2 & $<1,0$ & $<1,0$ & $<1,0$ & 4,9 & $1,3(27 \%)$ & 43,6 & 11,4 & $<1,0$ & 171 & $<1,0$ & $<1,0$ & $<1,0$ \\
\hline 3 & 8,4 & $<1,0$ & 78,3 & 5,1 & $<1,0$ & 33,9 & 21,6 & $<1,0$ & 179 & 1,4 & $<1,0$ & 66,7 \\
\hline 4 & 18,0 & $<1,0$ & 404 & 12,2 & $<1,0$ & 152 & 19,4 & $<1,0$ & 285 & 3,8 & $<1,0$ & 243 \\
\hline 5 & 9,9 & $<1,0$ & 258 & 15,0 & $<1,0$ & 149 & 12,3 & $<1,0$ & 418 & 4,3 & $<1,0$ & 507 \\
\hline 6 & $<1,0$ & $<1,0$ & $<1,0$ & 24,4 & $<1,0$ & 294 & 101 & $1,5(1 \%)$ & 3209 & 23,3 & $1,6(7 \%)$ & 1205 \\
\hline 7 & 9,4 & $<1,0$ & 221 & 11,9 & $<1,0$ & 129 & 31,0 & $<1,0$ & 1176 & 7,3 & $<1,0$ & 787 \\
\hline 8 & 19,0 & $<1,0$ & 257 & 15,3 & $<1,0$ & 176 & 29,4 & $<1,0$ & 1014 & 63,8 & $18,0(28 \%)$ & 5388 \\
\hline 9 & 4,7 & $<1,0$ & 67,3 & 2,5 & $<1,0$ & 24,4 & 5,3 & $<1,0$ & 260 & $<1,0$ & $<1,0$ & $<1,0$ \\
\hline 10 & 34,6 & $<1,0$ & 448 & 4,3 & $<1,0$ & 97,1 & 29,3 & $<1,0$ & 1825 & 8,4 & $<1,0$ & 1233 \\
\hline 11 & 36,2 & $<1,0$ & 818 & 6,5 & $1,3(20 \%)$ & 146 & 5,3 & $<1,0$ & 307 & 6,3 & $<1,0$ & 815 \\
\hline 12 & 17,8 & $<1,0$ & 297 & 6,4 & $<1,0$ & 84,4 & 27,2 & $<1,0$ & 631 & 3,1 & $<1,0$ & 350 \\
\hline 13 & 17,5 & $<1,0$ & 196 & 7,0 & $<1,0$ & 153 & 6,8 & $<1,0$ & 276 & 3,5 & $<1,0$ & 416 \\
\hline 14 & 17,5 & $<1,0$ & 402 & 8,9 & $<1,0$ & 216 & 20,1 & $<1,0$ & 300 & 2,3 & $<1,0$ & 216 \\
\hline 15 & 10,1 & $<1,0$ & 260 & 14,1 & $<1,0$ & 162 & 15,2 & $<1,0$ & 498 & 4,3 & $<1,0$ & 550 \\
\hline 16 & 466 & $43,8(9 \%)$ & 10173 & 489 & $26,2(5 \%)$ & 44076 & 638 & $136(21 \%)$ & 28685 & 795 & $503(63 \%)$ & 2254 \\
\hline 17 & 16,2 & $<1,0$ & 183 & 8,5 & $<1,0$ & 600 & 7,4 & $<1,0$ & 400 & 25,5 & $1,3(5 \%)$ & 1008 \\
\hline 18 & 4,7 & $<1,0$ & 137 & 8,8 & $1,6(18 \%)$ & 266 & 19,6 & $<1,0$ & 1127 & 4,8 & $<1,0$ & 475 \\
\hline 19 & 36,0 & $<1,0$ & 473 & 8,1 & $<1,0$ & 676 & 23,0 & $<1,0$ & 1294 & 12,5 & $<1,0$ & 1352 \\
\hline 20 & $<1,0$ & $<1,0$ & $<1,0$ & $<1,0$ & $<1,0$ & $<1,0$ & $<1,0$ & $<1,0$ & $<1,0$ & $<1,0$ & $<1,0$ & $<1,0$ \\
\hline 21 & $<1,0$ & $<1,0$ & $<1,0$ & 7,6 & $<1,0$ & 203 & 7,0 & $<1,0$ & 352 & 5,0 & $<1,0$ & 666 \\
\hline
\end{tabular}

${ }^{1}$ não determinado pela baixa quantidade de material particulado $(<0,0001 \mathrm{~g})$. 
Tabela 5. Teores pseudototais (PTOT) e trocáveis (TROC) de $\mathrm{Pb}\left(\mathrm{mg} \mathrm{kg}^{-1}\right)$ nas amostras de sedimento

\begin{tabular}{|c|c|c|c|c|c|c|c|c|}
\hline \multirow[b]{3}{*}{ Ponto } & \multicolumn{8}{|c|}{ Mês de coleta } \\
\hline & \multicolumn{2}{|c|}{ Maio } & \multicolumn{2}{|c|}{ Setembro } & \multicolumn{2}{|c|}{ Novembro } & \multicolumn{2}{|c|}{ Janeiro } \\
\hline & PTOT & TROC & PTOT & TROC & PTOT & TROC & PTOT & TROC \\
\hline 1 & 95,8 & $<0,1$ & 90,8 & $<0,1$ & 22,9 & $<0,1$ & 127 & $<0,1$ \\
\hline 2 & 3,9 & $<0,1$ & 14,9 & $<0,1$ & 19,2 & $<0,1$ & 21,4 & $<0,1$ \\
\hline 3 & 6,8 & $<0,1$ & 78,0 & $<0,1$ & 15,9 & $<0,1$ & 55,4 & $<0,1$ \\
\hline 4 & 162 & $<0,1$ & 118 & $<0,1$ & 111 & $<0,1$ & 99,4 & $<0,1$ \\
\hline 5 & 10653 & 7,1 & 6268 & 8,4 & 9224 & 11,5 & 19113 & 6,3 \\
\hline 6 & 2073 & 1,7 & 3867 & 2,4 & 1396 & 3,2 & 6886 & 2,3 \\
\hline 7 & 17741 & 5,1 & 4348 & 1,7 & 3620 & 2,2 & 16750 & 6,0 \\
\hline 8 & 5021 & $<0,1$ & 2211 & $<0,1$ & 4961 & 0,7 & 6307 & 6,2 \\
\hline 9 & 38,1 & $<0,1$ & 42,9 & $<0,1$ & 50,7 & $<0,1$ & 43,4 & $<0,1$ \\
\hline 10 & 29,1 & $<0,1$ & 40,4 & $<0,1$ & 33,4 & $<0,1$ & 31,4 & $<0,1$ \\
\hline 11 & 221 & 0,7 & 121 & $<0,1$ & 179 & $<0,1$ & 78,2 & $<0,1$ \\
\hline 12 & 273 & $<0,1$ & 635 & $<0,1$ & 235 & $<0,1$ & 475 & 1,6 \\
\hline 13 & 394 & 0,2 & 337 & 0,2 & 622 & 0,2 & 203 & $<0,1$ \\
\hline 14 & 904 & 2,4 & 261 & $<0,1$ & 8549 & 47,9 & 1146 & 0,8 \\
\hline 15 & 2029 & 2,6 & 3689 & 2,4 & 3950 & 25,0 & 6135 & 3,1 \\
\hline 16 & 21631 & 471 & 19638 & 246 & 12530 & 199 & 24300 & 241 \\
\hline 17 & 26,4 & $<0,1$ & 17,5 & $<0,1$ & 18,9 & 3,3 & 23,9 & $<0,1$ \\
\hline 18 & 690 & 3,4 & 16,2 & $<0,1$ & 740 & 3,5 & 686 & 1,2 \\
\hline 19 & 21,3 & $<0,1$ & 16,5 & $<0,1$ & 5,6 & $<0,1$ & 15,0 & $<0,1$ \\
\hline
\end{tabular}

com maior teor total na água (novembro) e teores pseudototais de $\mathrm{Pb}$ nos sedimentos (maio) para o ponto 4 também reflete a alta afinidade do metal às partículas sólidas e o baixo tamponamento do sistema: adsorção específica, com ligação química entre o $\mathrm{Pb}$ e a superfície dos coloides ${ }^{33}$ dos sedimentos.

Quando os teores pseudototais e trocáveis de $\mathrm{Pb}$ nos sedimentos são mais elevados, como encontrado na amostra 16 (saturação dos grupos hidroxilados de adsorção específica da superfície dos coloides), ${ }^{34}$ verifica-se que a comunicação e o tamponamento entre os sedimentos e a coluna d'água é maior; os maiores teores totais e pseudototais do metal para a água e sedimentos, respectivamente, foram obtidos para a coleta em janeiro. Na adsorção não específica ou por complexo de esfera externa, os metais traços são apenas atraídos eletrostaticamente pelas cargas negativas das argilas e coloides orgânicos dos sedimentos, o que permite a troca pelo $\mathrm{Ba}^{2+}$ da solução extratora de $\mathrm{BaCl}_{2} 0,1 \mathrm{~mol} \mathrm{~L}^{-128}$ e torna esse método um bom indicador das formas de $\mathrm{Pb}$ e $\mathrm{Zn}$ mais facilmente liberadas para a coluna d'água. Por se tratar de uma região com ocorrência de rochas carbonáticas, ${ }^{32}$ espera-se contínua lixiviação de $\mathrm{Ca}^{2+} \mathrm{e}$ $\mathrm{Mg}^{2+}$ dos solos e na água superficial e subterrânea esses cátions podem facilmente deslocar o $\mathrm{Pb}^{2+}$ e o $\mathrm{Zn}^{2+}$ adsorvidos por esfera externa nos sedimentos.

$\mathrm{Na}$ linha de drenagem representada pelos pontos 1 a 4 verifica-se exemplo típico da influência do teor de argila nos teores pseudototais de $\mathrm{Pb}$ dos sedimentos. $\mathrm{Na}$ coleta de janeiro, o ponto 3 possuía mais que o dobro de $\mathrm{Pb}$ que o ponto 2. Contudo, devido aos menores teores de argila no segundo $\left(94 \mathrm{~g} \mathrm{~kg}^{-1}\right.$ contra $259 \mathrm{~g} \mathrm{~kg}^{-1}$ no ponto 3 - Tabela 2), tem-se uma inversão nos teores do metal quando se expressam os resultados apenas em função da fração mais fina (ponto 2 - $228 \mathrm{mg}$ $\mathrm{kg}^{-1}$ de argila e ponto 3 - $214 \mathrm{mg} \mathrm{kg}^{-1}$ de argila). Essa transformação ( $\mathrm{Pb}$ do sedimento para a fração argila) foi obtida pela expressão: [(teor pseudototal de $\mathrm{Pb}$ do sedimento/teor de argila no sedimento, em $\left.\mathrm{g} \mathrm{kg}^{-1}\right)$ x 1000]. Como resultado prático, a fração argila do local 2 (em menor quantidade) está mais contaminada com $\mathrm{Pb}$ que o local 3. Essa relação se fundamenta na premissa que os metais traços nos sedimentos estão associados apenas às partículas coloidais (alta área superficial específica e CTC). Um evento de transporte seletivo de sedimentos mais finos da rede de drenagem para o Rio Ribeira iria resultar em uma maior contaminação pelo sedimento removido do ponto 2 .

A água subterrânea (ponto 5) apresentou teor total de $\mathrm{Pb}$ entre 4,3 e $15,0 \mu \mathrm{g} \mathrm{L}{ }^{-1}$, sendo o metal encontrado apenas na fração particulada. O sedimento do ponto 5 apresentou elevados teores pseudototais de $\mathrm{Pb}$ em todas as amostras, com teores entre 6.268,9 e 19.113,0 mg $\mathrm{kg}^{-1}$. Contudo, os teores trocáveis foram baixos $\left(6,30 \mathrm{a} 11,5 \mathrm{mg} \mathrm{kg}^{-1}\right)$. Nesse local, os sedimentos estão continuamente submersos, devido ao preenchimento dos túneis de mineração de cotas inferiores com água. Após 15 anos de finalização das atividades de mineração na área e constante troca de $\mathrm{Pb}$ entre sedimentos e coluna d'água (forma solúvel), com a saída contínua do metal mais fracamente ligado à fase sólida, resultou nos baixos níveis na água nos dias atuais e na falta de relação entre teor pseudototal de $\mathrm{Pb}$ no sedimento e na água. Dessa forma, a maior fonte de contaminação do Rio Ribeira proveniente das águas subterrâneas seria resultante de atividades que provocam a remobilização de partículas de sedimentos, principalmente argila, aumentando o $\mathrm{Pb}$ particulado e total.

A água dos pontos 6, 7 e 8 estava contaminada e os teores totais de $\mathrm{Pb}$ foram até 10 vezes acima do valor máximo estabelecido pela PMS 518/2004. O sedimento destes pontos também apresentou elevados teores de $\mathrm{Pb}$ total, reflexo da comunicação advinda do ponto 5 .

Após o encontro das duas redes de drenagem da área, a água superficial segue em direção ao Rio Ribeira; nesse trecho, em sequência têm-se os pontos 12, 13, 14 e 15 (Tabela 1). De acordo com os dados apresentados por Andrade et al.,${ }^{35}$ o maior teor de $\mathrm{Pb}$ biodisponível (maior mobilidade ambiental, extraído com $\mathrm{HNO}_{3} 4,0$ mol L-1 fervente) foi obtido para os solos argilosos no entorno da fábrica $(9.823,5$ $\left.\mathrm{mg} \mathrm{kg}^{-1}\right)$. Segundo esses autores, a principal fonte da contaminação desses solos foram as fumaças emitidas pelas chaminés da fábrica ( $\mathrm{Pb}$ particulado).

Nos sedimentos, os teores pseudototais de $\mathrm{Pb}$ dos pontos 12 a 15 foram menores do que dos pontos 6,7 e 8 . Isso sugere que a contaminação proveniente da nascente $\mathrm{A}$ é maior que aquela da nascente B, ou seja, houve um efeito de diluição da segunda drenagem ( 9 a 11). Os solos do lado direito da linha de drenagem, pontos 9 a 11, 
são arenosos,,$^{20} \mathrm{o}$ que refletiu no menor teor de argila desses pontos em relação aos pontos 1 a 4 (Tabela 2). Então, por efeito de mistura do sedimento dessas duas drenagens, a textura dos sedimentos dos pontos 12 a 15 foi intermediária.

O ponto 16 (água pluvial que passa pela fábrica) apresentou os maiores teores de $\mathrm{Pb}$ total na água em todas as amostragens, com valores que chegaram a 80 vezes acima do limite estabelecido pela PMS 518/2004. Este ponto é importante na dispersão de $\mathrm{Pb}$, pois, ao contrário dos demais locais de coleta, foram detectados elevados teores solúveis do metal, atingindo $503,4 \mu \mathrm{g} \mathrm{L}^{-1} \mathrm{em}$ janeiro. O sedimento no ponto 16 também apresentou os maiores teores pseudototais (máximo de 24.300,0 mg kg-1) e trocáveis de $\mathrm{Pb}$ (máximo de 471,9 $\mathrm{mg} \mathrm{kg}^{-1}$ ). Em estudos preliminares (dados não publicados), o teor de $\mathrm{Pb}$ total dos resíduos na forma de pó no pátio da fábrica foi da ordem de $200.000 \mathrm{mg} \mathrm{kg}^{-1}$.

A comparação entre os teores pseudototais de $\mathrm{Pb}$ dos sedimentos com diferentes legislações ambientais internacionais indicam que os pontos 5 a 8, 12 a 16 e 18 apresentam resultados acima dos valores orientadores da Espanha $\left(600 \mathrm{mg} \mathrm{kg}^{-1}\right)$, Holanda $\left(530 \mathrm{mg} \mathrm{kg}^{-1}\right)$, EUA (218 mg kg $\mathrm{mg}^{-1}$ ) e Canadá (112 $\left.\mathrm{mg} \mathrm{kg}^{-1}\right)$. Cotta et al. ${ }^{36}$ também observaram intensa contaminação dos sedimentos do Rio Betari, no Alto Ribeira. Este curso d'água também sofre influência das atividades de mineração, apresentando teor máximo de $\mathrm{Pb}$ pseudototal de $7.569,8 \mathrm{mg} \mathrm{kg}^{-1}$.

Os pontos 17 e 19, que correspondem à água do Rio Ribeira, apresentaram teores de $\mathrm{Pb}$ total acima de $10 \mu \mathrm{g} \mathrm{L}^{-1}$, na maioria das amostragens. Entretanto, verifica-se que a maior fração de $\mathrm{Pb}$ está na forma particulada (máximo de $5,1 \%$ do $\mathrm{Pb}$ total está na forma solúvel). Se a água do rio for usada para o consumo humano, a simples decantação do material particulado melhoraria sua potabilidade. Em estudo realizado em 1986 no Rio Ribeira, a 65 km a montante da área de mineração, os teores totais de $\mathrm{Pb}$ na água foram baixos e variaram de 0,01 a $0,21 \mu \mathrm{g} \mathrm{L}{ }^{-1} \cdot{ }^{18} \mathrm{~A}$ água consumida pelos moradores do entorno da área, referente aos pontos 20 e 21, encontra-se dentro dos padrões nacionais de potabilidade para esse elemento.

\section{Zinco nas amostras de água e de sedimento}

Os pontos que apresentaram maiores concentrações de $\mathrm{Pb}$ (Tabelas 4 e 5) também apresentaram os teores mais elevados de Zn (Tabelas 6 e 7). A associação desses metais na área é reflexo da composição mineralógica dos minérios, classificados como fontes de $\mathrm{Pb}-\mathrm{Zn}$-Ag. ${ }^{16} \mathrm{O} \mathrm{Pb}$ solúvel correlacionou com Zn solúvel da água ( $\mathrm{r}$ $=0,79, p<0,001)$, da mesma forma que as formas trocáveis desses metais nos sedimentos $(\mathrm{r}=0,98, p<0,001)$. Em relação à dinâmica de $\mathrm{Pb}$ na água (Tabela 4) verificou-se percentagem muito maior de $\mathrm{Zn}$ total na forma solúvel (Tabela 6), o que indica interação mais fraca do segundo metal aos coloides do solo.

No ponto 1 (nascente A) verificou-se apenas $\mathrm{Zn}$ na fração total na água em janeiro $\left(3,8 \mu \mathrm{g} \mathrm{L^{-1 }}\right)$. No entanto, não foram detectadas formas solúveis do elemento. O ponto 9 (nascente $\mathrm{B}$ ) apresentou $\mathrm{Zn}$ em três amostragens, sendo que o maior teor total foi de $18,1 \mu \mathrm{g} \mathrm{\textrm {L } ^ { - 1 }}$ em maio. Apesar disso, os teores obtidos se encontram muito abaixo do estabelecido pela Resolução CONAMA 357/05 (180 $\left.\mu \mathrm{g} \mathrm{L}^{-1}\right)$ e Portaria $518\left(5 \mathrm{mg} \mathrm{L}^{-1}\right)$.

Os pontos 2, 3 e 4 apresentaram baixos teores do metal na água, e o ponto 5, com água subterrânea, apresentou teores totais que variaram de 22,6 a 39,2 $\mu \mathrm{g} \mathrm{L}^{-1}$. Como observado para $\mathrm{Pb}$, o ponto 5 apresentou altos teores pseudototais de $\mathrm{Zn}$ no sedimento.

$\mathrm{O}$ ponto 16 apresentou os maiores teores totais de $\mathrm{Zn}$ na água, com elevada participação da fração solúvel (até 54\%), e no sedimento. $\mathrm{O}$ tamponamento do Zn entre a água e o sedimento é indicado pelas correlações significativas entre o metal solúvel na água e os teores pseudototais $(\mathrm{r}=0,95, p<0,001)$ e trocáveis $(\mathrm{r}=0,96, p<0,001)$ nos sedimentos. Comparando os resultados dos sedimentos com o teor limite de qualidade estabelecido pela Espanha (3.000 mg kg-1),

Tabela 6. Teores de Zn total (TOT - $\left.\mu \mathrm{g} \mathrm{L}^{-1}\right)$, solúvel (SOL - $\mu \mathrm{g} \mathrm{L} \mathrm{L}^{-1}$ ) e particulado (PAR - $\left.\mu \mathrm{g} \mathrm{g}^{-1}\right)$ nas amostras de água

\begin{tabular}{|c|c|c|c|c|c|c|c|c|c|c|c|c|}
\hline \multirow[b]{3}{*}{ Ponto } & \multicolumn{12}{|c|}{ Mês de coleta } \\
\hline & \multicolumn{3}{|c|}{ Maio } & \multicolumn{3}{|c|}{ Setembro } & \multicolumn{3}{|c|}{ Novembro } & \multicolumn{3}{|c|}{ Janeiro } \\
\hline & TOT & SOL & PAR & TOT & SOL & PAR & TOT & SOL & PAR & TOT & SOL & PAR \\
\hline 1 & $<1,0$ & $<1,0$ & $<1,0$ & $<1,0$ & $<1,0$ & $<1,0$ & $<1,0$ & $<1,0$ & $<1,0$ & 3,8 & $<1,0$ & $\mathrm{nd}^{1}$ \\
\hline 2 & $<1,0$ & $<1,0$ & $<1,0$ & 11,5 & $6,9(60 \%)$ & 55,8 & 2,7 & $1,6(60 \%)$ & 18,2 & $<1,0$ & $<1,0$ & $<1,0$ \\
\hline 3 & 1,4 & $<1,0$ & 4,2 & 3 & $3,0(100 \%)$ & $\mathrm{nd}^{2}$ & 4,4 & $1,0(23 \%)$ & 29,6 & $<1,0$ & $<1,0$ & $<1,0$ \\
\hline 4 & 1,5 & $<1,0$ & 11,9 & 1,8 & $1,8(100 \%)$ & $\mathrm{nd}^{2}$ & $<1,0$ & $<1,0$ & $<1,0$ & 5,2 & $<1,0$ & 365 \\
\hline 5 & 36,4 & $7,9(22 \%)$ & 826 & 39,2 & $2,5(6,4 \%)$ & 392 & 22,6 & $15,4(68 \%)$ & 266 & 34,6 & $<1,0$ & 5169 \\
\hline 6 & $<1,0$ & $<1,0$ & $<1,0$ & 12,6 & $4,6(37 \%)$ & 100 & 23,4 & $4,0(17 \%)$ & 625 & 11,3 & $8,0(71 \%)$ & 183 \\
\hline 7 & 5,2 & $2,5(48 \%)$ & 71,1 & 7,5 & $2,7(36 \%)$ & 56,8 & 4,6 & $2,4(52 \%)$ & 86,3 & 5,0 & $<1,0$ & 500 \\
\hline 8 & 4,7 & $4,7(100 \%)$ & $\mathrm{nd}^{2}$ & 6,2 & $<1,0$ & 64,2 & 5,2 & $1,9(37 \%)$ & 117 & 15,8 & $<1,0$ & 1741 \\
\hline 9 & 18,1 & $2,0(11 \%)$ & 292 & 5,6 & $4,9(88 \%)$ & 11,4 & 2,2 & $2,1(95 \%)$ & 6,1 & $<1,0$ & $<1,0$ & $<1,0$ \\
\hline 10 & 21,1 & $2,5(12 \%)$ & 248 & $<1,0$ & $<1,0$ & $<1,0$ & 5,1 & $<1,0$ & 264 & 4,6 & $<1,0$ & 600 \\
\hline 11 & 19,6 & $19,6(100 \%)$ & $\mathrm{nd}^{2}$ & $<1,0$ & $<1,0$ & $<1,0$ & $<1,0$ & $<1,0$ & $<1,0$ & $<1,0$ & $<1,0$ & $<1,0$ \\
\hline 12 & 12,7 & $2,6(20 \%)$ & 178 & 10,1 & $1,5(15 \%)$ & 134 & $<1,0$ & $<1,0$ & $<1,0$ & 1,5 & $<1,0$ & 83,3 \\
\hline 13 & 8,3 & $1,4(17 \%)$ & 82,1 & 3,9 & $1,1(29 \%)$ & 71,8 & 2,5 & $1,0(40 \%)$ & 71,4 & 1,2 & $<1,0$ & 33,3 \\
\hline 14 & 15,5 & $4,1(27 \%)$ & 278 & 10,3 & $1,8(18 \%)$ & 232 & 2,3 & $<1,0$ & 20,5 & 1,6 & $<1,0$ & 100 \\
\hline 15 & 5,9 & $2,9(49 \%)$ & 85,7 & 7,8 & $4,9(63 \%)$ & 36,0 & 9,2 & $3,4(37 \%)$ & 203,5 & 17,6 & $10,4(59 \%)$ & 1200 \\
\hline 16 & 472 & $253(54 \%)$ & 5277 & 672 & $131(19 \%)$ & 51523 & 631 & $262(42 \%)$ & 21085 & 958 & $314(33 \%)$ & 4973 \\
\hline 17 & 16,0 & $1,7(11 \%)$ & 172 & $<1,0$ & $<1,0$ & $<1,0$ & $<1,0$ & $<1,0$ & $<1,0$ & 6,6 & $2,6(39 \%)$ & 166 \\
\hline 18 & 2,3 & $2,2(96 \%)$ & 3,7 & 3,1 & $3,1(100 \%)$ & $\mathrm{nd}^{2}$ & 5,3 & $2,4(45 \%)$ & 175 & 2,0 & $<1,0$ & 125 \\
\hline 19 & 7,7 & $3,3(43 \%)$ & 59,5 & 5,9 & $5,9(100 \%)$ & $\mathrm{nd}^{2}$ & $<1,0$ & $<1,0$ & $<1,0$ & 2,1 & $<1,0$ & 129 \\
\hline 20 & 887 & $3,3(1 \%)$ & 14369 & 26,4 & $6,2(23 \%)$ & 631 & 43,3 & $13,8(32 \%)$ & 983 & 42,3 & $<1,0$ & 137666 \\
\hline 21 & 96,9 & $24,3(25 \%)$ & 4033 & 91,1 & $46,8(51 \%)$ & 1363 & 51,2 & $48,7(95 \%)$ & 147 & 40,9 & $40,7(100 \%)$ & $\mathrm{nd}^{2}$ \\
\hline
\end{tabular}

${ }^{1}$ não determinado pela baixa quantidade de material particulado $(<0,0001 \mathrm{~g}) .{ }^{2}$ aproximadamente $100 \%$ do Zn encontrava-se na fração dissolvida (SOL). 
Tabela 7. Teores pseudototais (PTOT) e trocáveis (TROC) de $\mathrm{Zn}\left(\mathrm{mg} \mathrm{kg}^{-1}\right)$ nas amostras de sedimento

\begin{tabular}{|c|c|c|c|c|c|c|c|c|}
\hline \multirow[b]{3}{*}{ Ponto } & \multicolumn{8}{|c|}{ Mês de coleta } \\
\hline & \multicolumn{2}{|c|}{ Maio } & \multicolumn{2}{|c|}{ Setembro } & \multicolumn{2}{|c|}{ Novembro } & \multicolumn{2}{|c|}{ Janeiro } \\
\hline & PTOT & TROC & PTOT & TROC & PTOT & TROC & PTOT & TROC \\
\hline 1 & 53,9 & $<0,1$ & 64,5 & $<0,1$ & 55,0 & $<0,1$ & 50,4 & $<0,1$ \\
\hline 2 & $<0,1$ & $<0,1$ & $<0,1$ & $<0,1$ & $<0,1$ & $<0,1$ & $<0,1$ & $<0,1$ \\
\hline 3 & $<0,1$ & $<0,1$ & 31,2 & $<0,1$ & $<0,1$ & $<0,1$ & 2,6 & $<0,1$ \\
\hline 4 & 12,7 & $<0,1$ & 0,8 & 0,1 & 4,1 & $<0,1$ & 2,7 & $<0,1$ \\
\hline 5 & 2387 & 1,2 & 925 & 7,6 & 3621 & 13,7 & 3829 & 4,7 \\
\hline 6 & 163 & 0,9 & 486 & $<0,1$ & 160 & 0,8 & 625 & $<0,1$ \\
\hline 7 & 1149 & 0,5 & 966 & $<0,1$ & 505 & 0,6 & 1167 & 1,3 \\
\hline 8 & 153 & $<0,1$ & 103 & $<0,1$ & 284 & 0,4 & 316 & 2,6 \\
\hline 9 & $<0,1$ & $<0,1$ & $<0,1$ & $<0,1$ & 1,9 & $<0,1$ & $<0,1$ & $<0,1$ \\
\hline 10 & $<0,1$ & $<0,1$ & $<0,1$ & $<0,1$ & $<0,1$ & $<0,1$ & $<0,1$ & $<0,1$ \\
\hline 11 & 6,5 & $<0,1$ & 6,4 & $<0,1$ & 9,2 & 0,3 & $<0,1$ & $<0,1$ \\
\hline 12 & 23,6 & $<0,1$ & 46,7 & $<0,1$ & 28,9 & 1,9 & 18,1 & $<0,1$ \\
\hline 13 & 149 & $<0,1$ & 40,8 & $<0,1$ & 54,5 & 4,7 & 18,2 & $<0,1$ \\
\hline 14 & 81,7 & $<0,1$ & 41,6 & $<0,1$ & 350 & 5,7 & 47,0 & $<0,1$ \\
\hline 15 & 341 & 1,4 & 379 & 1,1 & 548 & 4,5 & 293 & $<0,1$ \\
\hline 16 & 32376 & 446 & 41669 & 261 & 32960 & 278 & 22130 & 331 \\
\hline 17 & 6,9 & 4,3 & 1,4 & 1,2 & 2,5 & 1,7 & 7,1 & $<0,1$ \\
\hline 18 & 412 & 0,5 & 222 & 0,4 & 847 & 4,4 & 262 & $<0,1$ \\
\hline 19 & 2,4 & 1,2 & 1,1 & $<0,1$ & 0,7 & $<0,1$ & 3,8 & $<0,1$ \\
\hline
\end{tabular}

mais restritivo em relação aos EUA, Holanda e Canadá, observa-se que o ponto 16 , em todas as amostragens, e o ponto 5 , em novembro e janeiro, são considerados poluídos. Quando se observam os valores recomendados estabelecidos pela Holanda $\left(720 \mathrm{mg} \mathrm{kg}^{-1}\right)$ e pelo EUA (410 $\mathrm{mg} \mathrm{kg}^{-1}$ ) verifica-se a inclusão de vários outros pontos como tendo concentração de $\mathrm{Zn}$ no sedimento acima do valor de referência (pontos 6, 8, 13, 14, 15, e 18). Cotta et al. ${ }^{36}$ encontraram teores de Zn nos sedimentos do Rio Betari, afluente do Rio Ribeira, teores pseudototais de $\mathrm{Zn}$ variando de 330,0 a $5.497,4 \mathrm{mg} \mathrm{kg}^{-1}$.

Com relação à água distribuída para a população foram verificadas concentrações de Zn, ponto 20 (maio), acima do limite estabelecido pelo CONAMA (180 $\left.\mu \mathrm{g} \mathrm{L}^{-1}\right)$. Segundo esse critério, a água desta nascente não poderia ser classificada nas classes 1 e 2 .

Para o ponto 21 , a forma solúvel de $\mathrm{Zn}$ foi mais importante (25 a $100 \%$ do total) e no ponto 20 a maior parte se encontra na forma particulada.

\section{CONCLUSÕES}

$\mathrm{Na}$ maioria dos pontos de coleta, os teores de $\mathrm{Pb}$ na água foram superiores a $10 \mu \mathrm{g} \mathrm{L}^{-1}$. Contudo, a água consumida pela população do entorno da fábrica desativada estava dentro dos padrões nacionais de potabilidade. O mesmo não se verificou para a água do Rio Ribeira. Houve acúmulo progressivo do metal na água da linha de drenagem que corta a área de disposição de resíduos da metalurgia. Para o Zn, apenas na coleta de maio os teores na água consumida pela população foram superiores a $180 \mu \mathrm{g} \mathrm{L^{-1 }}$.

Os sedimentos contaminados com $\mathrm{Pb}$ (teor pseudototal máximo de $19.113,0 \mathrm{mg} \mathrm{kg}^{-1}$ ) nas linhas de drenagem a montante da fábrica apresentaram baixos teores do metal na forma trocável (máximo de $47,9 \mathrm{mg} \mathrm{kg}^{-1}$ ), o que indica sua forte associação com a fração coloidal e baixo tamponamento de formas solúveis na coluna d'água.

Os elevados teores de $\mathrm{Pb}$ nos sedimentos e nas águas (máximo de $471,9 \mu \mathrm{g} \mathrm{L}^{-1}$ ) no ponto às margens do Rio Ribeira, de convergência da água pluvial que passa pela fábrica, determinaram que essa forma de contaminação está sendo a mais deletéria para o ambiente.

Em relação à dinâmica de $\mathrm{Pb}$ na água verificou-se percentagem muito maior de $\mathrm{Zn}$ total na forma solúvel, o que indica interação mais fraca do segundo metal aos coloides do solo.

\section{MATERIAL SUPLEMENTAR}

Está disponível em http://quimicanova.sbq.org.br, na forma de arquivo pdf, com acesso livre.

\section{REFERÊNCIAS}

1. Hortellani, M. A.; Sarkins, J. E. S; Abessa, D. M. S.; Sousa, E. C. P. M.; Quim. Nova 2008, 31, 10.

2. Yabe, M. J. S.; Oliveira, E.; Quim. Nova 1998, 21, 551.

3. Rietzler, A. C.; Fonseca, A. L.; Lopes, G. P.; Braz. J. Biol. 2001, 61, 363.

4. Bosso, S. T.; Enzweiler, J.; Angélica, R.; Water, Air, Soil Pollut. 2008, 195, 257.

5. Paolielo, M. M. B.; Chasin, A. A. M; Ecotoxicologia do chumbo e seus compostos, CRA: Salvador, 2001.

6. Silva, E. F.; Almeida, S. F.; Nunes, M. L; Luís, A. T.; Borg, F.; Hedlund, M.; Patinha, C.; Teixeira, P.; Sci. Total Environ. 2009, 407, 5620.

7. Oliveira, M. R.; Tese de Doutorado, Universidade Federal de Minas Gerais, Brasil, 2007.

8. Bosso, S. T.; Enzweiler, J.; Quim. Nova 2008, 31, 394

9. http://www.mma.gov.br/port/conama/res/res05/res35705.pdf, acessada em Outubro 2010.

10. Lemes, M. J. L.; Figueiredo, F. P. M.; Pires, M. A. F.; Quim. Nova 2003 , $26,356$.

11. Jesus, H. C.; Mendonça, A. S. F.; Zandonade, E.; Abreu, E.; Quim. Nova 2004, 27, 378 .

12. Santana, G. P.; Barroncas, P. S. R.; Acta Amaz. 2007, 37, 111.

13. Alves, F. L.; Cadore, S.; Jardim, W. F.; Arruda, M. A. Z.; J. Braz. Chem. Soc. 2001, 12, 799.

14. Gardolinski, P. C. F. C.; Packer, A. P.; Almeida, C. R.; Giné, M. F.; J. Braz. Chem. Soc. 2002, 13, 375

15. Lima, M. C.; Giacomelli, M. B. O.; Stüpp, V.; Roberge, F. D.; Quim. Nova 2001, 24, 734.

16. Corsi, A. C.; Landim, P. M. B.; Geociências 2003, 22, 49. 
17. Cassiano, A. M.; Tese de Doutorado, Universidade de São Paulo, Brasil, 2001.

18. Eysink, G. G. J.; Rev. CETESB Tec. Amb. 1988, 2, 6.

19. Kummer, L.; Dissertação de Mestrado, Universidade Federal do Paraná, Brasil, 2008.

20. Barros, Y. J.; Melo, V. F.; Dionísio, J. A.; Caron, L.; Oliveira, E. B.; Azevedo, J. C. R.; Souza, L. C. P.; R. Bras. Ci. Solo 2010, 34, 1397.

21. Barros, Y. J.; Melo, V. F.; Sautter, K. D.; Buschle, B.; Oliveira, E. B.; Azevedo, J. C. R.; Souza, L. C. P.; R. Bras. Ci. Solo 2010, 34, 1412.

22. Paolielo, M. M. B.; Capitani, E. M.; Cunha, F. G.; Matsuo, T.; Carvalho, M. F.; Sakuma, A.; Figueiredo, B. R.; Environ. Res. 2002, 88, 120.

23. Cunha, F. G.; Tese de Doutorado, Universidade Estadual de Campinas, 2003.

24. Maack, R.; Geografia Física do Estado do Paraná, Secretaria da Cultura e Esporte do Paraná: Curitiba, 1981.

25. Apha; Standard Methods for the Examination of Water and Wastewater, $19^{\text {th }}$ ed., American Public Health Association; American Water Works Association; Water Environment Federation: Washington, 1995.

26. Embrapa; Manual de métodos de análises de solo, $2^{\mathrm{a}}$ ed., Embrapa: Rio de Janeiro, 1997.
27. http://www.epa.gov/epawaste/hazard/testmethods/sw846/pdfs/3051a. pdf, acessada em Janeiro 2010.

28. Hendershott, W. H.; Duquete, M.; Soil Sci. Soc. Am. J. 1986, 50, 605.

29. http://www.epa.gov/osw/hazard/testmethods/sw846/pdfs/3015a.pdf, acessada em Janeiro 2010.

30. http://bvsms.saude.gov.br/bvs/publicacoes/portaria_518_2004.pdf, acessada em Outubro 2010

31. Andrade, M. G.; Melo, V. F.; Gabardo, J.; Souza, L. C. P.; Reissmann, C. B.; R. Bras. Ci. Solo 2009, 3, 1879.

32. Oliveira, M. A. F.; Maniesi, V.; Teixeira, W.; Daitx, E. C.; Geologia USP Série Científica 2002, 2, 161.

33. Kalbasi, M.; Racz, G. J.; Rudgers, L. A.; Soil Sci. 1978, 125, 146.

34. McBride, M. B.; Environmental chemistry of soils, Oxford University Press: New York, 1994.

35. Andrade, M. G.; Melo, V. F.; Souza, L.C.P.; Gabardo, J.; Reissmann, C. B.; R. Bras. Ci. Solo 2009, 33, 1889.

36. Cotta, J. A. O.; Rezende, M. O. O.; Piovani, M. R.; Quim. Nova 2006, $29,40$. 


\section{CHUMBO E ZINCO EM ÁGUAS E SEDIMENTOS DE ÁREA DE MINERAÇÃO E METALURGIA DE METAIS}

Vander de Freitas Melo*, Maísa de Andrade, Araína Hulmann Batista e Nerilde Favaretto

Departamento de Solos e Engenharia Agrícola, Universidade Federal do Paraná, Rua dos Funcionários, 1540, 80035-050 Curitiba - PR, Brasil

Marco Tadeu Grassi e Mônica Soares de Campos

Departamento de Química, Universidade Federal do Paraná, CP 19081, 81531-990 Curitiba - PR, Brasil
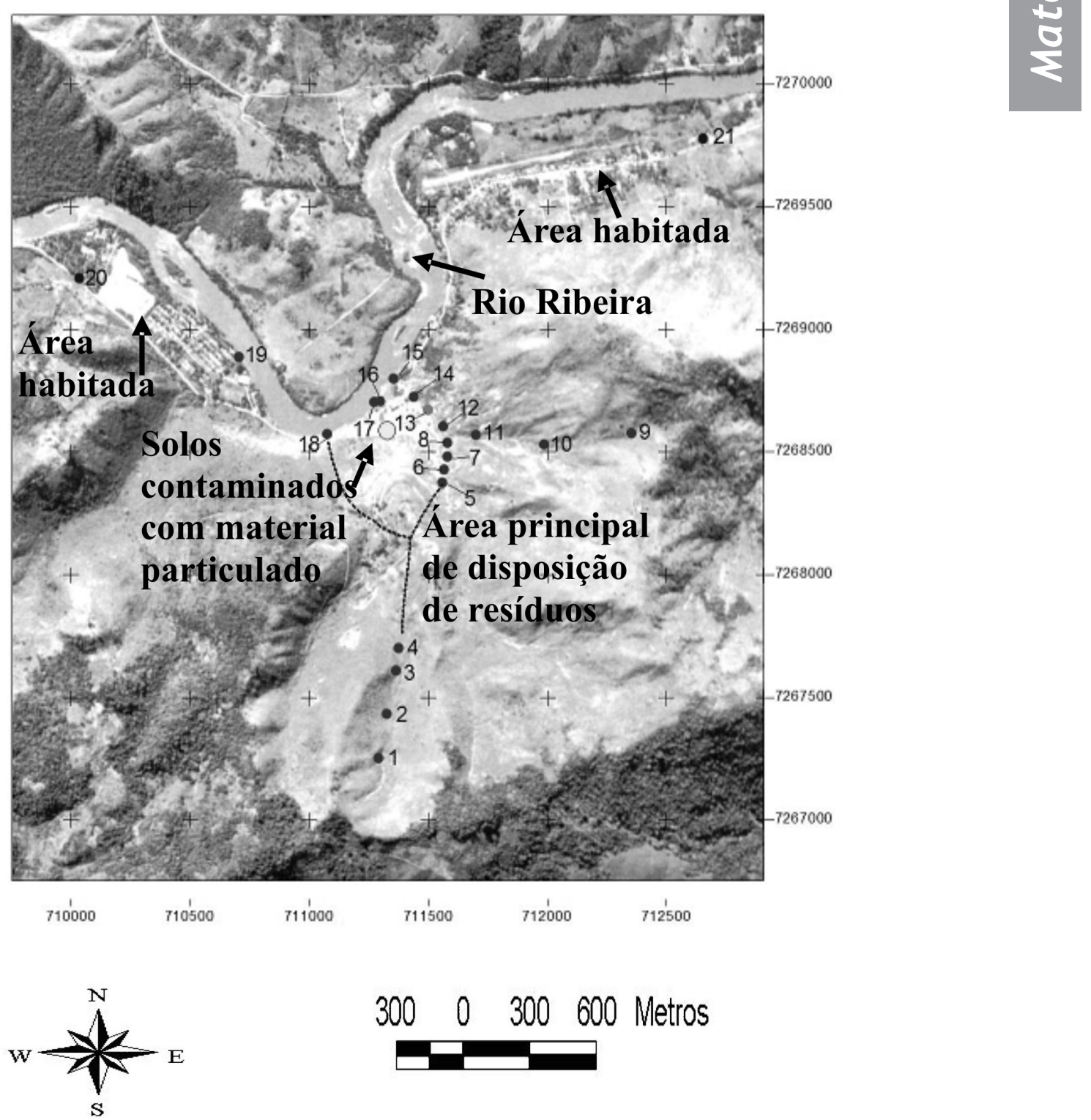

Sistema de Projeção: Universal Transversa de Mercator (UTM). Datum: SAD-69

Figura 1S. Fotografia aérea georreferenciada com a localização dos pontos de coleta das amostras a partir das duas únicas nascentes da área (1 e 9): pontos 1 a 19 - coleta de água e sedimento; pontos 20 e 21 - coleta de água. A fábrica desativada é representada pelo círculo maior e claro próximo ao Rio Ribeira. As linhas pontilhadas indicam os locais onde a água deixa de escorrer na superfície e entra nos antigos túneis de mineração (água subterrânea). O maior volume de rejeitos sólidos da metalurgia de metais traços estava espalhado sobre os solos entre os pontos 4 e 5 e os solos argilosos próximos à fábrica foram contaminados com Pb particulado das chaminés

*e-mail: vanderfm@ufpr.br 